\title{
Performance of four ischemic stroke prognostic scores in a Brazilian population
}

\author{
Desempenho de quatro escalas de prognóstico de $\mathrm{AVCl}$ em uma população brasileira \\ Gustavo W. Kuster ${ }^{1,2,3}$, Lívia A. Dutra ${ }^{1,2,4}$, Israel P. Brasil1,2, Evelyn P. Pacheco ${ }^{1,2}$, Márcio J. C. Arruda1 , Cristiane \\ Volcov', Renan B. Domingues ${ }^{1,2,5}$
}

\begin{abstract}
Objective: Ischemic stroke (IS) prognostic scales may help clinicians in their clinical decisions. This study aimed to assess the performance of four IS prognostic scales in a Brazilian population. Method: We evaluated data of IS patients admitted at Hospital Paulistano, a Joint Commission International certified primary stroke center. In-hospital mortality and modified Rankin score at discharge were defined as the outcome measures. The performance of National Institutes of Health Stroke Scale (NIHSS), Stroke Prognostication Using Age and NIHSS (SPAN-100), Acute Stroke Registry and Analysis of Lausanne (ASTRAL), and Totaled Health Risks in Vascular Events (THRIVE) were compared. Results: Two hundred six patients with a mean \pm SD age of $67.58 \pm 15.5$ years, being $55.3 \%$ male, were included. The four scales were significantly and independently associated functional outcome. Only THRIVE was associated with in-hospital mortality. With area under the curve THRIVE and NIHSS were the scales with better performance for functional outcome and THRIVE had the best performance for mortality. Conclusion: THRIVE showed the best performance among the four scales, being the only associated with in-hospital mortality.
\end{abstract}

Keywords: ischemic stroke, prognostic scales, NIHSS, THRIVE, Brazil.

\section{RESUMO}

Objetivo: Escalas de avaliação prognóstica do acidente vascular cerebral isquêmico (AVCI) podem ajudar decisões clinicas. O objetivo deste estudo foi avaliar o desempenho de quatro escalas prognósticas em uma população brasileira. Método: Foram avaliados os dados de pacientes admitidos com AVCI no Hospital Paulistano, um hospital acreditado pela "Joint Commission International". A mortalidade intra-hospitalar e a escala de Rankin foram definidos como desfechos de evolução clínica. O desempenho de quatro escalas: National Institutes of Health Stroke Scale (NIHSS), Stroke Prognostication Using Age and NIHSS (SPAN-100), Acute Stroke Registry and Analysis of Lausanne (ASTRAL) e Totaled Health Risks in Vascular Events (THRIVE) foi comparado. Resultados: Foram incluídos duzentos e seis pacientes, com uma idade média de 67,58 \pm 15,5 anos, sendo 55,3\% dos sexo masculino. Todas as quatro escalas associaram-se de forma independente com prognóstico funcional. Apenas o THRIVE correlacionou-se com a mortalidade hospitalar. O THRIVE e o NIHSS tiveram melhor desempenho para prognóstico funcional e o THRIVE teve o melhor desempenho para mortalidade pela área sob a curva. Conclusão: O THRIVE mostrou-se a escala com melhor performance, sendo a única correlacionada com a mortalidade hospitalar.

Palavras-chave: acidente vascular cerebral isquêmico, escalas de prognóstico, NIHSS, THRIVE, Brasil.

The prediction of ischemic stroke outcome may help physicians in their acute treatment decisions. Some scores have been developed for predicting prognosis after ischemic stroke (IS). The National Institutes of Health Stroke Scale (NIHSS) strongly predicts stroke prognosis, is well validated, and is routinely used, both in clinical and research settings ${ }^{1}$. The Stroke Prognostication Using Age and NIHSS (SPAN-100) index, which combines age and NIH Stroke Scale, was shown to be a simple method for estimating the clinical response and risk of hemorrhagic complications after tissue-type plasminogen activator (tPA) for acute IS ${ }^{2}$. The Acute Stroke Registry and Analysis of Lausanne (ASTRAL) score (age, severity, time delay between stroke onset and admission, range of visual deficit, acute glucose, and levels of consciousness)

${ }^{1}$ Hospital Paulistano, AMIL, Sao Paulo SP, Brazil;

${ }^{2}$ Programa Integrado de AVC (PIAVEN), AMIL, Sao Paulo SP, Brazil;

${ }^{3}$ Faculdade de Medicina do ABC, Departamento de Neurologia, Sao Paulo SP, Brazil;

«Universidade Federal de São Paulo, Departamento de Neurologia, Sao Paulo SP, Brazil;

5Universidade Federal de Minas Gerais, Programa de Neurociências, Belo Horizonte MG, Brazil.

Correspondence: Renan Barros Domingues; Rua Almeida Torres, 119 / apto 133 / torre A; 01530-010 São Paulo SP, Brasil; E-mail: contato@renandomingues.med.br Conflict of interest: There is no conflict of interest to declare.

Support: Dr. Domingues was a recipient of a CAPES Post-Doctoral scholarship in 2014.

Received 04 November 2014; Received in final form 14 August 2015; Accepted 03 September 2015. 
is a six items score, at hospital admission, that showed to be potentially useful for clinical practice ${ }^{3}$. Totaled Health Risks in Vascular Events (THRIVE) score (totaled health risks in vascular events) is calculated with age, NIHSS, and the presence of hypertension, diabetes mellitus, and atrial fibrillation and was validated to predicting clinical outcome and hemorrhagic transformation in patients receiving tPA and showed to be a simple score to help clinicians to estimate outcome and death after acute IS $^{4}$. These four scores were not yet compared and their reproducibility has been tested only in Europe, North America, and Asia.

Stroke is the leading cause of death and disability in Brazil $^{5}$. IS accounts for more than $80 \%$ of all stroke types in Brazil $^{6}$. In recent years, a growing number of stroke centers have been settled in this country ${ }^{7}$. Consequently, an increasing number of patients with acute IS have benefited from validated therapies, including the use of $\mathrm{PA}^{8}$. However, only few studies have evaluated IS outcome in Brazil ${ }^{9}$ and none of them have assessed the utility of prognostic scores in a Brazilian population. The aim of the present study was to compare the performance of NIHSS, SP-100, ASTRAL, and THRIVE scores to predict in-hospital mortality and functional outcome in an acute IS Brazilian population.

\section{METHOD}

Charts of patients assisted at Hospital Paulistano, a Joint Commission International certified stroke center located in the central region of São Paulo, between 2012 and 2014, were reviewed. This study protocol was approved by the Ethics Committee on Research of Hospital Paulistano (Amil Stroke Network).

\section{Patients and procedures}

We retrospectively evaluated the clinical records of all patients admitted with suspected or confirmed stroke. The diagnoses were made by neurologists with expertise in cerebrovascular disease through clinical and radiological evaluation. All patients underwent at least one computed tomography scan of the brain (CT scan) to confirm the diagnosis. Only patients diagnosed as having IS were included in the analysis.

Age, gender, stroke risk factors (hypertension, smoking, familial history of vascular diseases, diabetes, previous stroke or transient ischemic attack) were compiled. Data on clinical presentation, NIHSS, capillary glucose level, and vital signs on admission were also recorded.

\section{Prognostic scores}

The prognostic scales as well as their cut-offs were used as described in previous studies. According to NIHSS patients were allocated into three subgroups ( 0 to 5,6 to 15 , and $\geq 16)^{1}$. SPAN-100 was calculated by the sum of the age in years and the NIHSS. The adopted cut off for SPAN-100 was 100 and patients were divided into two groups, one with
SPAN-100 $<100$ and other with SPAN-100 $\geq 100^{2}$. ASTRAL score was calculated by the sum of age (1 point for every 5 years), NIHSS, time delay from onset to admission ( 0 points when onset to admission was $<3$ hours, 2 points when it was more than 3 hours), range of visual deficit (0 points in the absence of visual field defect, 2 points for any stroke-related visual field defect), acute glucose $<3.7 \mathrm{mmol} / \mathrm{L}$ or $>7.3 \mathrm{mmol} / \mathrm{L}$ (1 point), and decreased level of consciousness (3 points). An ASTRAL score $\geq 31$ was adopted as an indicator of unfavourable outcome ${ }^{3}$. THRIVE score was calculated by the sum of age (1 point for age of 60 to 79 years, 2 points for an age $\geq 80$ years), 2 points for a NIHSS of 11 to 20,4 points for a NIH $\geq 21$, and 1 point for each hypertension, diabetes mellitus, and fibrillation. The THRIVE ranged from 0 to 9 and the patients were divided in three subgroups ( 0 to 2,3 to 5 , and 6 to 9$)^{4}$.

\section{Data analysis}

Statistical analysis was performed using SPSS version 15.0 for Windows. The confidence interval was of $95 \%$ and the significance level was set at $\mathrm{p}<0.05$. Normality was assessed using the Kolmogorov-Smirnov test. In-hospital mortality and modified Rankin score (mRs) at discharge, whereby the patients were divided in two groups, one with $\mathrm{mRS} \leq 2$ and other with $\mathrm{mRs}>2$, were defined as outcomes measures. Univariate analysis was carried out with Mann-Whitney test for continuous variables and chi-square for categorical variables. A binary logistic regression analysis was performed with mRS and in-hospital mortality as dependent variables. A sensitivity analysis was conducted to compare the three scores. Area under the receiver operator curves (AUROC) and $95 \%$ CIs were calculated as a measure of predictive ability. According to the AUROC result the predictive ability was considered excellent (0.9 to 0.99 ), good (0.8 to 0.89 ), fair (0.7 to 0.79 ), poor (0.6 to 0.69 ), and failure (0.5 to 0.59 ).

\section{RESULTS}

Three hundred fifty one patients were admitted with stroke or suspected stroke in the period of the study. Among them, two hundred six patients $(58.7 \%)$ had the diagnosis of IS and were included in the analysis. The mean \pm standard deviation (SD) age was $67.58 \pm 15.5$ years and $55.3 \%$ of patients were male. Table 1 shows the comparisons of the characteristics of patients who had favorable functional outcome ( $m R s ~ \geq 2$ ) with those of patients with poor functional outcome (mRs $>2$ ). By univariate analysis, patients with $\mathrm{mRs}>2$ had higher age $(p=0.002)$, higher percentage of NIHSS $\geq 16$ at admission $(\mathrm{p}<0.001)$, higher percentage of SPAN-100 $\geq 100$ $(\mathrm{p}<0.001)$, higher percentage of ASTRAL $\geq 31(\mathrm{p}<0.001)$, and higher percentages of THRIVE 3 to 5 and THRIVE $>5$ ( $p<0.001)$. After adjusted analysis, none of these variables were independently associated with $\mathrm{mRs}>2$. Table 2 shows the comparisons of baseline characteristics of survivors and 
patients who died during hospitalization. No significant differences were found between these two groups.

NIHSS subgroups were fairly predictive of $\mathrm{mRs}>2$ (AUROC 0.754; 0.644 to $0.810, \mathrm{p}<0.001$ ) and were not predictive of in-hospital mortality (AUROC $0.546 ; 0.409$ to 0.683 , $\mathrm{p}=0.495)$. SPAN- $100 \geq 100$ was poorly predictive of poor functional outcome (AUROC 0.591; 0.5 to $0.683, \mathrm{p}=0.041$ ) and was not predictive of in-hospital mortality (AUROC 0.520; 0.386 to $0.654, p=0.766$ ). ASTRAL $\geq 31$ was poorly predictive of mRs $>2$ (AUROC 0.668; 0.577 to $0.758, p<0.001$ ) and not predictive of in-hospital mortality (AUROC 0.556; 0.428 to $0.705, p=0.321)$. THRIVE subgroups were fairly predictive of mRs > 2 (AUROC 0.720; 0.641 to 0.800, p < 0.001) and were poorly predictive of in-hospital mortality (AUROC 0.636; 0.513 to $0.758, \mathrm{p}=0.042$ ) (Figure).

\section{DISCUSSION}

In the present study none of the scores demonstrated good or excellent ability to predict in-hospital mortality and functional outcome in the studied population. THRIVE score was the only score to predict death but the accuracy was poor. THRIVE

Table 1. Clinical characteristics of patients according to the mRs at hospital discharge.

\begin{tabular}{|c|c|c|c|c|}
\hline & $m R s \leq 2$ & $m R s>2$ & $p$ & $p^{*}$ \\
\hline Age & $68(18-93)$ & 76.5 (23-95) & 0.002 & 0.080 \\
\hline \multicolumn{5}{|l|}{ Gender } \\
\hline Male & $42.2 \%$ & $13.1 \%$ & & \\
\hline Female & $29.6 \%$ & $15.0 \%$ & 0.122 & 0.994 \\
\hline Hypertension & $66.9 \%$ & $74.1 \%$ & 0.403 & 0.309 \\
\hline Diabetes & $34.5 \%$ & $37.9 \%$ & 0.632 & 0.542 \\
\hline Smoking & $16.3 \%$ & $13.8 \%$ & 0.831 & 0.357 \\
\hline $\begin{array}{l}\text { Family history of } \\
\text { stroke }\end{array}$ & $8.1 \%$ & $6.9 \%$ & 1.000 & 0.291 \\
\hline Previous stroke or TIA & $27.7 \%$ & $31 \%$ & 0.732 & 0.624 \\
\hline Atrial fibrillation & $31.6 \%$ & $40.8 \%$ & 0.283 & 0.832 \\
\hline Time of symptoms & $36(30-17280)$ & $575(60-7200)$ & 0.072 & 0.996 \\
\hline Wake-up stroke & $22.97 \%$ & $36.2 \%$ & 0.079 & 0.796 \\
\hline $\begin{array}{l}\text { Glucose at } \\
\text { admission }\end{array}$ & $113(76-321)$ & $115(60-271)$ & 0.336 & 0.774 \\
\hline SPAN-100 $\geq 100$ & $0.67 \%$ & $18.96 \%$ & $<0.001$ & 0.774 \\
\hline ASTRAL $\geq 31$ & $2.7 \%$ & $36.2 \%$ & $<0.001$ & 0.999 \\
\hline \multicolumn{5}{|l|}{ NIHSS } \\
\hline 0 to 5 & $83.24 \%$ & $38.46 \%$ & & \\
\hline 6 to 15 & $10.86 \%$ & $26.92 \%$ & $<0.001$ & 0.999 \\
\hline$\geq 16$ & $2.9 \%$ & $34.62 \%$ & & \\
\hline \multicolumn{5}{|l|}{ THRIVE } \\
\hline 0 to 2 & $62.16 \%$ & $24.14 \%$ & & \\
\hline 3 to 5 & $37.17 \%$ & $58.62 \%$ & $<0.001$ & 0.228 \\
\hline 6 to 9 & $0.67 \%$ & $17.24 \%$ & & \\
\hline
\end{tabular}

mRs:modified Rankin score;TIA:transient ischemic accident;SPAN-100:stroke prognostication using age and NIH stroke scale; NIHSS: National Institutes of Health stroke scale; ASTRAL: Acute Stroke Registry and Analysis of Lausanne; THRIVE: totaled health risks in vascular events; $p$ : Mann-Whitney test; $p *$ : Binary Logistic Regression. and NIHSS were fairly accurate to predict worse functional outcome at hospital discharge. In previous studies THRIVE was shown to be a good predictor of clinical outcome, hemorrhagic transformation, and outcome after endovascular ${ }^{10}$ and intravenous stroke treatment ${ }^{11,12}$. This score has been previously tested in North American, European, and Asian populations; however, to the best of our knowledge, this was the first study to evaluate this score in a South American population. The THRIVE score can be easily calculated and can be quickly performed with data routinely obtained during the initial clinical evaluation, such as age, NIHSS, and risk factors (hypertension, diabetes, and atrial fibrillation), without the need of neuroimaging and laboratory testing ${ }^{4}$. Despite the fact THRIVE was the score with better performance, it had not an AUROC above the threshold of 0.8 , which is required for clinical use. These results should be interpreted cautiously since our study was small and was carried out in a single institution. Future studies are needed to better assess and validate the use of THRIVE in the Brazilian population.

SPAN-100 did not predict well in-hospital mortality and functional outcome. This finding is in line with a previous study also demonstrating poor performance of SPAN-100 to predict outcomes at 3 and 12 months in

Table 2. Clinical characteristics of patients according to the in-hospital death.

\begin{tabular}{|c|c|c|c|c|}
\hline & Survivors & In hospital death & $p$ & $p^{*}$ \\
\hline Age & $68(24-93)$ & $4(0-21)$ & 0.827 & 0.253 \\
\hline \multicolumn{5}{|l|}{ Gender } \\
\hline Male & $50.2 \%$ & $6 \%$ & \multirow{2}{*}{1.000} & \multirow{2}{*}{0.862} \\
\hline Female & $39.3 \%$ & $4.5 \%$ & & \\
\hline Hypertension & $66.7 \%$ & $81 \%$ & 0.223 & 0.615 \\
\hline Diabetes & $36.7 \%$ & $33.3 \%$ & 0.816 & 0.824 \\
\hline Smoking & $16.2 \%$ & $14.3 \%$ & 1.000 & 0.516 \\
\hline Family history & $7.8 \%$ & $4.8 \%$ & 1.000 & 0.787 \\
\hline $\begin{array}{l}\text { Previous stroke } \\
\text { orTIA }\end{array}$ & $27.2 \%$ & $38.1 \%$ & 0.312 & 0.313 \\
\hline Atrial fibrillation & $33.1 \%$ & $41.2 \%$ & 0.590 & 0.299 \\
\hline Time of symptoms & $455(30-17280)$ & $430(30-4320)$ & 0.793 & 0.519 \\
\hline Wake-up stroke & $28.9 \%$ & $14.3 \%$ & 0.200 & 0.463 \\
\hline $\begin{array}{l}\text { Glucose at } \\
\text { admission }\end{array}$ & $114.5(76-321)$ & $111(60-147)$ & 0.669 & 0.392 \\
\hline SPAN-100>100 & $5.56 \%$ & $9.52 \%$ & 0.363 & 0.999 \\
\hline ASTRAL > 31 & $10.56 \%$ & $23.8 \%$ & 0.145 & 0.971 \\
\hline \multicolumn{5}{|l|}{ NIHSS } \\
\hline 0 to 5 & $10.37 \%$ & $66.66 \%$ & \multirow{3}{*}{0.497} & \multirow{3}{*}{0.649} \\
\hline 6 to 15 & $15.24 \%$ & $14.29 \%$ & & \\
\hline$\geq 16$ & $74.39 \%$ & $19.05 \%$ & & \\
\hline \multicolumn{5}{|l|}{ THRIVE } \\
\hline $0-2$ & $55 \%$ & $28.6 \%$ & & \\
\hline $3-5$ & $40 \%$ & $61.9 \%$ & 0.069 & 0.148 \\
\hline $6-9$ & $5 \%$ & $9.5 \%$ & & \\
\hline
\end{tabular}

mRs:modified Rankin score;TIA:transient ischemic accident;SPAN-100:stroke prognostication using age and NIH stroke scale; NIHSS: National Institutes of Health stroke scale; ASTRAL: Acute Stroke Registry and Analysis of Lausanne; THRIVE: totaled health risks in vascular events; $p$ : Mann-Whitney test; $p^{\star}$ : Binary Logistic Regression. 
A

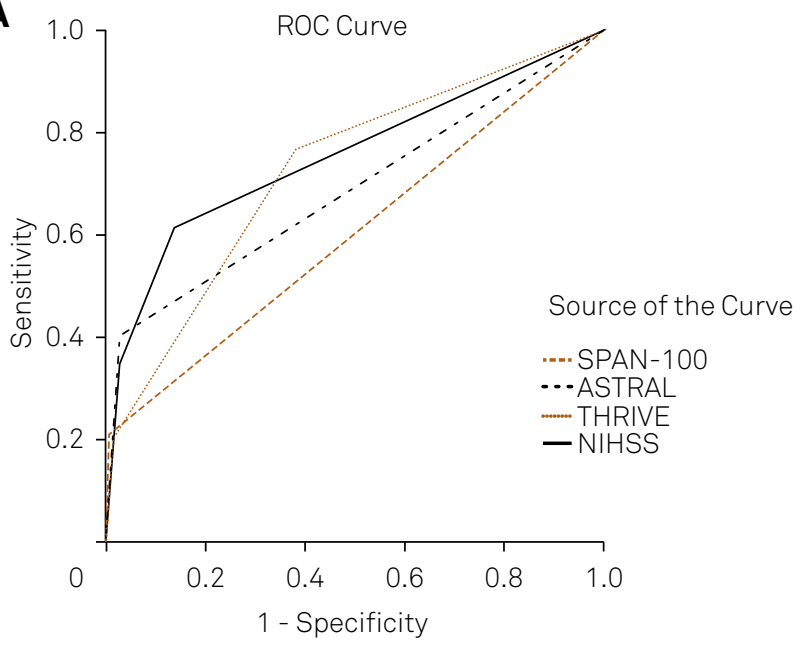

B

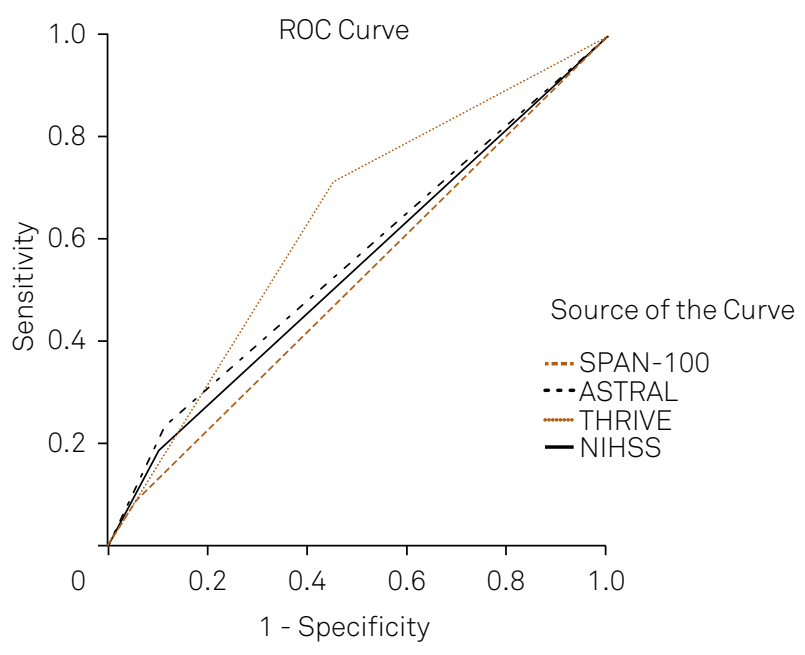

Figure. Comparison of National Institutes of Health Stroke Scale (NIHSS), Stroke Prognostication Using Age and NIHSS (SPAN-100), Acute Stroke Registry and Analysis of Lausanne (ASTRAL), and Totaled Health Risks in Vascular Events (THRIVE) ability to predict (A) mRS at hospital discharge and (B) in-hospital death.
Chinese population ${ }^{12}$. ASTRAL score was previously shown to be a reliable predictor of 5-year functional outcome and mortality ${ }^{13}$ and a good predictor of unfavorable outcome at 3 and 12 months in Chinese population ${ }^{14,15}$. In the present study ASTRAL poorly predicted functional outcome and did not predict in-hospital mortality. The difference between our findings and the previous studies evaluating ASTRAL performance must be viewed with caution. In the present study we evaluated in-hospital outcomes, ie, functional status at discharge and in-hospital mortality, while the previous studies evaluated prognosis at 3 months or more. It is possible that these differences explain why none of the tested variables were independently associated with functional outcome and in-hospital mortality.

Our study has limitations that deserve comment. First, the number of included patients was small. Consequently, these results need confirmation in larger stroke registries or in prospective studies. Also, we did not follow the patients after discharge, so there are not data concerning 3- and 12-month outcomes. As strengthens of the study it must be mentioned the homogeneity of the sample, since all the patients were from a single institution and the same stroke team evaluated all patients.

The use of prognostic scores may help clinicians, since the clinical evaluation alone is inaccurate ${ }^{16}$. To contribute to clinicians, the score must be highly effective in prognostic evaluation and easily applied during the first clinical evaluation. The use of such scales, in this context, can help better target the use of therapeutic resources, especially in countries where limited resources to treat stroke patients are available, such as the low to medium income countries. The present results do not allow, to date, the recommendation of these scores for clinical use in Brazilian population. Future and larger studies are still necessary to reassess the accuracy of these scales, specially THRIVE which showed to be the most promising of the four evaluated scales.

\section{References}

1. Adams HP Jr, Davis PH, Leira EC, Chang KC, Bendixen BH, Clarke WR et al. Stroke Scale score strongly predicts outcome after stroke: a report of the trial of org 10172 in Acute Stroke Treatment (TOAST). Neurology. 1999;53(1):126-31. doi:10.1212/WNL.53.1.126

2. Saposnik G, Guzik AK, Reeves M, Ovbiagele B, Johnston SC. Stroke prognostication using age and $\mathrm{NIH}$ stroke scale: SPAN-100. Neurology. 2013;80(1):21-8. doi:10.1212/WNL.0b013e31827b1ace

3. Ntaios G, Faouzi M, Ferrari J, Lang W, Vemmos K, Michel P. An integer-based score to predict functional outcome in acute ischemic stroke: the ASTRAL score. Neurology. 2012;78(24):1916-22. doi:10.1212/WNL.0b013e318259e221

4. Lei C, Wu B, Liu M, Chen Y, Yang H, Wang D et al. Totaled health risks in vascular events score predicts clinical outcomes in patients with cardioembolic and other subtypes of ischemic stroke. Stroke. 2014;45(6):1689-94. doi:10.1161/STROKEAHA.113.004352
5. Garritano CR, Luz PM, Pires ML, Barbosa MT, Batista KM. Analysis of the mortality trend due to cerebrovascular accident in Brazil in the XXI century. Arq Bras Cardiol. 2012;98(6):519-27. doi:10.1590/S0066-782X2012005000041

6. Fernandes TG, Goulart AC, Campos TF, Lucena NM, Freitas KL, Trevisan $\mathrm{CM}$ et al. Early stroke case-fatality rates in three hospital registries in the Northeast and Southeast of Brazil. Arq Neuropsiquiatr. 2012;70(11):869-73. doi:10.1590/S0004-282X2012001100009

7. Rocha MS, Almeida AC, Abath Neto O, Porto MP, Brucki SM. Impact of stroke unit in a public hospital on length of hospitalization and rate of early mortality of ischemic stroke patients. Arq Neuropsiquiatr. 2013;71(10):774-9. doi:10.1590/0004-282X20130120

8. Moro CH, Gonçalves AR, Longo AL, Fonseca PG, Harger R, Gomes DB et al. Trends of the incidence of ischemic stroke thrombolysis over seven years and one-year outcome: a population-based study in Joinville, Brazil. Cerebrovasc Dis Extra. 2013;3(1):156-66. doi:10.1159/000356984 
9. Carvalho JJ, Alves MB, Viana GÁ, Machado CB, Santos

$\mathrm{BF}$, Kanamura AH et al. Stroke epidemiology, patterns of management, and outcomes in Fortaleza, Brazil: a hospitalbased multicenter prospective study. Stroke. 2011;42(12):3341-6. doi:10.1161/STROKEAHA.111.626523

10. Flint AC, Cullen SP, Rao VA, Faigeles BS, Pereira VM, Levy El et al. The THRIVE score strongly predicts outcomes in patients treated with the Solitaire device in the SWIFT and STAR trials. Int J Stroke. 2014;9(6):698-704. doi:10.1111/ijs.12292

11. Flint AC, Gupta R, Smith WS, Kamel H, Faigeles BS, Cullen SP et al. The THRIVE score predicts symptomatic intracerebral hemorrhage after intravenous tPA administration in SITS-MOST. Int J Stroke. 2014;9(6):705-10. doi:10.1111/ijs.12335

12. Flint AC, Faigeles BS, Cullen SP, Kamel H, Rao VA, Gupta $R$ et al. THRIVE score predicts ischemic stroke outcomes and thrombolytic hemorrhage risk in VISTA. Stroke. 2013;44(12):3365-9. doi:10.1161/STROKEAHA.113.002794
13. Pan Y, Jing J, Zhang R, Zhao X, Liu L, Wang H et al. Poor performance of stroke prognostication using age and National Institutes of Health Stroke Scale-100 to predict 3- and 12-month outcomes of ischemic stroke in China National Stroke Registry. J Stroke Cerebrovasc Dis. 2014;23(9):2335-40. doi:10.1016/j.jstrokecerebrovasdis.2014.04.031

14. Papavasileiou V, Milionis H, Michel P, Makaritsis K, Vemmou A, Koroboki E et al. ASTRAL score predicts 5-year dependence and mortality in acute ischemic stroke. Stroke. 2013;44(6):1616-20. doi:10.1161/STROKEAHA.113.001047

15. Liu G, Ntaios G, Zheng H, Wang Y, Michel P, Wang DZ et al. External validation of the ASTRAL score to predict 3- and 12-month functional outcome in the China National Stroke Registry. Stroke. 2013;44(5):1443-5. doi:10.1161/STROKEAHA.113.000993

16. Merino JG, Silver B, Wong E, Demaerschalk B, Tamayo A, Hachinski V. Physician knowledge of the benefits, risks, and contraindications of tissue plasminogen activator for acute ischemic stroke. Stroke. 2001;32(9):2208-9 